\title{
Zooming in on embodied social sensemaking: Mapping the design space in the context of videoconferencing
}

\author{
Jelle van Dijk* \\ Human Centred Design group, University of Twente \\ jelle.vandijk@utwente.nl
}

\begin{abstract}
Embodied sensemaking theory is thoroughly social: we make sense of the world in interaction with others. Various designs have been proposed to scaffold 'embodied social sensemaking'. Yet the details of such scaffolding need elaboration. For example, what happens in remote settings, when bodies cannot engage directly? This paper investigates, through design, how interactive artifacts scaffold embodied social sensemaking. The aim is to establish clearer links between theory and design. Twenty-four embodied interaction prototypes were created to support remote videoconferencing by design students who were also, necessarily, active videoconferencing users during a COVID-19 lockdown. A reflective ordering process revealed a design space made up of six phenomenal aspects and three basic types of scaffolding. The analysis adds further details to existing design frameworks for embodied sensemaking. The paper provides guidance to designers who aim to create meaningful and theoretically grounded embodied augmentations of remote social interaction technologies.
\end{abstract}

\section{CCS CONCEPTS}

- Human-centered computing $\rightarrow$ Interaction design; Interaction design theory, concepts and paradigms; Human computer interaction (HCI); HCI theory, concepts and models; Human computer interaction (HCI); Interaction paradigms; Collaborative interaction; Human computer interaction (HCI); Interaction paradigms; Mixed / augmented reality.

\section{KEYWORDS}

embodied social sensemaking, embodied sensemaking, social interaction, video-conferencing, remote interaction, design framework, tangible interaction, embodied interaction

\section{ACM Reference Format:}

Jelle van Dijk*. 2022. Zooming in on embodied social sensemaking: Mapping the design space in the context of videoconferencing. In Sixteenth International Conference on Tangible, Embedded, and Embodied Interaction (TEI '22), February 13-16, 2022, Daejeon, Republic of Korea. ACM, New York, NY, USA, 10 pages. https://doi.org/10.1145/3490149.3501324

This work is licensed under a Creative Commons

Attribution-NonCommercial-ShareAlike International 4.0 License.

TEI '22, February 13-16, 2022, Daejeon, Republic of Korea

(c) 2022 Copyright held by the owner/author(s).

ACM ISBN 978-1-4503-9147-4/22/02.

https://doi.org/10.1145/3490149.3501324

\section{INTRODUCTION}

Over the years, a body of work has developed that brings theories of embodied, situated and distributed cognition, ecological psychology and embodied phenomenology to the field of tangible and embodied interaction [1-8]. One core shared premise in these theories is that the way in which human beings make sense of the world, is fundamentally embodied and situated [9]. The accompanying promise for design is that tangible and embodied interaction technologies are particularly well-placed to capitalize on these theories, and that these theories can inform the design of new and meaningful embodied interactions.

The present paper focuses on the social aspect of embodied sensemaking, or, to put it the other way around, on the embodied character of social sensemaking. Drawing on [10], Hummels and Van Dijk describe the social aspect of embodied sensemaking as a 'social coordination' that happens in the immediate moment-a self-organizing coupling emerging from ongoing social interactions between living, active human bodies [11] [4]. In [11] also a slower process of 'relationship forming' is described, growing in the background of the realtime moments of social coupling [11]. It is assumed that such 'social couplings' can be scaffolded [4] by well-designed interactive technology. However, the frameworks presented in [11] and [4] lack detail that would help to guide the actual design of such social scaffolds. The present Research-throughDesign study dives deeper into how embodied theory may inform various ways in which technologies might scaffold embodied social sensemaking.

As a concrete context of practice we turned to videoconferencing. Video-mediated communication has a long research history [12-14], but the COVID-19 crisis has brought videoconferencing to our collective awareness, at least in privileged countries. Many more people now have first-hand experiences in trying to relate socially to others through a video-connection. More specifically, the pandemic has had tremendous impact on the daily (educational) experience of students, forced to remain in isolation and attend lectures and workshops online. In a master course on embodied interaction we decided to turn this unfortunate situation to our advantage and address the challenges we were ourselves experiencing by designing for them. There was a clear pragmatic reason for this topic, as it was the one practice readily available in the pandemic. Yet it is also an interesting, radical context to explore, as it demands of us to become very concrete about what is meant with terms like 'embodied sensemaking' and 'social coupling', given these are to be supported between isolated people interacting remotely through screens. There seems to be a common sense intuition that certain aspects of social interaction 'in real life' are just impossible to re-enact through the screen. If this is true, could embodied sensemaking theory explain why? Alternatively, it 
may be that real life encounters happen to offer certain embodied qualities that play a role in social sensemaking, which are currently, but not necessarily, lacking in remote videoconferencing. If that is the case, could embodied sensemaking theory explain what is lacking in remote settings, and can it help to design embodied augmentations of videoconferencing to overcome at least some of its limitations? These are the sorts of questions we took as inspiration for the present study.

\subsection{The social in embodied sensemaking.}

A theoretical basis for the social nature of embodied sensemaking is found in situated cognition theory, which explains how any form of human sensemaking is always already situated in social practices [4] [5], [15]. In situated cognition, artifacts typically act as objects coordinating between people, for example by anchoring attention or by creating a publicly visible 'action space' to ground social coordination [1]. Distributed cognition theory similarly describes (configurations of) objects as sites of external knowledge, which distribute sensemaking over a collective of people and things [7]. More recently, under the name of participatory sensemaking, De Jaegher developed an enactivist account of social cognition [10]. Her theory applies principles of self-organization and action-perception coupling to social situations. In participatory sensemaking, people use their skilled bodies to dynamically and unreflectively 'couple to' others, like an improvised dance. The resulting couplings constitute both 'making sense of one another', as well as collaboratively 'making sense of the situation' [16]. Furthermore, from phenomenology we know that the skilled, sense-making body may be 'extended' by incorporating artifacts (cf. the hammer in Heidegger and the blind-man's stick in Merleau-Ponty) [2]. We may thus envision technological 'bodily extensions' to play a part in participatory sensemaking between people. In summary, the theory offers a perspective in which technological artifacts are configuring and anchoring social situations, as well as being incorporated as extended aspects of skilled bodies in the participatory couplings between people. The next question is how these theoretical foundations concretely translate to design.

\subsection{Related design work.}

Work on remote embodied social interaction already has quite a history, of which we can only review a small selection. A famous example of 'mediated social touch' [17] is the wooden rollerbank InTouch [18]. One rollerbank is electronically actuated to mimick the rolling pattern generated by hand at another, remote copy, and vice versa, producing a direct physical connection. InTouch would be a good example of a scaffold for the action-perception couplings described in participatory sensemaking theory. Many variations were developed since [19]. A remote physical connection is also used to enhance an emotional bond between between family members or loved ones. Especially hugging is a popular theme, as in the hugging shirt [20] pyjama [21] or teddy-bear [22]. Other designs enable social-emotional connection via vibrotactile smarthpones [23], gloves [24], more clothing [25] [26], drinking cups [27] chairs [28] or even beds [29]. Various modalities of input and output are explored [30]. Sometimes, like InTouch, input and output modalities are unified; more often, physical input (touch, squeezing, etc) is translated into a less tangible output such as light or sound. There seems to be a bias towards designing tools for sending 'affective messages' rather than working out how signals sent back and forth would sustain a social coupling over time, between people, or even in larger groups [31] [24].

Another longstanding research line investigates video-mediated interaction as such. Ethnographical work shows how people readily incorporate standard live video-connection to increase remote awareness, which can support "informal interactions, spontaneous connections, and the development of shared cultures-all important aspects of maintaining working relationships" [32]. People are also shown to adapt to the constraints of the new medium, by developing new social embodied routines [33] [12]. Several studies redesign the video interface itself, for example to strengthen the formation of action-perception couplings building on Gibson's ecological perception theory [34]. In relation to this [35] and [36] designed embodied video-conferencing with mechanical movement of the video-screen in response to head gestures of a remote person. Telepresence video-robots (remotely controlled video-screens on wheels) were shown to enhance feelings of mutal trust [37].

Finally, various embodied interaction designs for sensemaking and social interaction in groups are relevant for remote collaboration as well. [38]. Some designs introduce peripheral interactive objects to enhance group awareness [39],[40], or create action affording interfaces to drive self-organizing group dynamics [31]. Participatory Sensemaking theory has been used to explain how tangible representations scaffold collaboration in groups [41],[42]. Recent applications like Mozzilla Hubs and Spatial Chat can be seen as 'embodied moves' away from standard video-conferencing. In these applications closeness between avatars in a virtual space maps onto volume level of a live audio connection: one walks towards a person to better hear them speak [43].

\section{OBJECTIVES}

Using design action as a vehicle for the inquiry, the present study explores how to support remote embodied social sensemaking in an educational setting. On the basis of various design explorations the underlying question is addressed: how does embodied theory inform the design of embodied scaffolds for social sensemaking, or in other words: how can the expression of embodied theory into concrete use artifacts help us understand in more detail what the social aspect of embodied sensemaking is about? The central aim is therefore to get more precise on the question of how embodied social sensemaking can be scaffolded by interactive tangible and embodied technologies (in particular, in remote settings), and the results will add some detail to the existing embodied sensemaking framework as presented in Hummels and Van Dijk [4]. Note that the results are not meant as prescriptions for how to design, rather the structured design space that results from the inquiry offers a theoretically and experientially grounded 'thinking tool' [44] to guide the design process [45], much in Lucy Suchman's sense of how models and plans may guide, yet never prescribe, skilled, situated action [5]. 


\section{METHODS}

We engaged in a Research-through-Design process that integrates embodied theory and lived experience through the design of concrete artifacts and reflecting on the outcomes.

To be clear, the approach taken is not an empirical investigation of how design students use theory in design. Neither is it an observational study of user experiences of video conferencing. Rooted explicitly in phenomenology and in the tradition of Research-through-Design [48], it presents a conceptual inquiry that uses design action and lived experiences to ground the analysis. This is done in a two-step process. In step 1, a wide array of creative outcomes is created, informed by embodied theory, actual, lived user experiences; building on creative design skill and the local technological opportunities available. Following Hengeveld and colleagues, the resulting prototypes "embody .. the design rationale ... [i.e], the choices a designer-researcher makes based on the knowledge (s)he has at a specific moment." [46]. In the second phase, these design outcomes are used as building blocks for creating a meaningful order in a conceptual design space that serves to translate embodied theory to concrete interaction design. This results in further clarity on the phenomenon of (remote) embodied social sensemaking, and the various scaffolding roles interactive technology may have. We now describe the two phases in more detail.

In phase I, 24 design trajectories each produced one final prototype. Each design exploration was executed by a pair of one master student in interaction technology and one student of industrial product design, all of whom also active daily users of video-conferencing due to the pandemic. Of these designer-users 29 identified as male, 23 as female, 1 as non-binary; mean age of 23 (range $19-28$ ); 8 were non-EU residents, 45 EU residents of which 36 had the Dutch nationality. All designer-users provided informed consent for their work to be used in this research and received credit points for the course. Note that this research does not present the designs as such as a research outcome or assess the quality of the designs: the design outcomes function here as cognitive tools for developing structure in a conceptual design space. Each team received the following brief:

"All of us have now experienced that video-conferencing works, in a practical sense. Yet at the same time, the intuition, that for real human contact and connection, you still need to be physically in the same space, has not disappeared. Imagine a Zoom session like the ones we are now having on a daily basis. What embodied, tangible interaction can you create trying to help people 'connect'? Through design, investigate: to what extent could crucial aspects of the phenomenal experience that we all know so well personally, the feeling you get when being physically together, be established at a distance, mediated by embodied interaction?"

Each trajectory lasted 8 weeks, with (at least) 3 iterations producing 2 intermediate lo-fi prototypes and one final, partially functional and/or Wizard of Oz prototype. An iteration consisted of (at least) auto-ethnographic observations, ideation, prototyping, literature research and a plenary peer-reflection session. All teams received 6 theory workshops on embodied interaction design and two Arduino Uno starter Kits ${ }^{1}$ plus an Arduino BLE Nano, Vibration Motor, RGB

\footnotetext{
${ }^{1}$ https://store.arduino.cc/genuino-starter-kit
}

led and Accelerometer. Teams were free to also use other prototyping materials and technologies. Regulations allowed teams to meet physically (keeping 1.5 meter distance), yet in practice the majority of communication happened through video-conferencing.

The resulting designs represent a diverse set of creative 'abductive leaps' [47]. For each team, converging on a prototype effectively meant to integrate in the act of design three things at minimum: 1 ) ones' own personal lived experiences of remote social sensemaking 2) embodied social sensemaking theory 3) design opportunities arising from the designers' skills and material and technological constraints. The overall constraining factor was provided by the use setting: education through videconferencing.

While each project converged onto one solution, the set as a whole represents an overall divergent, generative step of 'pressing into possibilities'. Grounded in design action, skill, technological opportunity, as well as in lived experiences within the actual use context, this is our designerly way to confront theory with practice [48], and transform it into a rich space of possibilities to be used in the next, analytic step [46].

In phase II, all design outcomes were gathered in a visual overview using Mural software ${ }^{2}$. First, all designs were annotated to describe the main interaction qualities, both particular details that seemed unique to the work as well as aspects that turned out to recur in similar ways in more than one project. Projects were also annotated focusing on main functionalities, and where possible were linked to existing design cases in the literature (either as being very similar or as posing an interesting variation). From this initial annotation various possible ways of clustering objects were found in order to detect overarching themes or categories. This finally resulted in a grid structure where the rows represent a number of distinctive aspects of the central phenomenon: remote social sensemaking (aspects that the designer-users had found relevant to address in their design project) and the columns represent different ways in which interactive technology within the set would be scaffolding the particular phenomenon in question. In this analysis we focused purely on analysing the design outcomes (i.e., contrasting and comparing the resulting designs).

\section{RESULTS}

The 24 designs are briefly explained in Table 1 . As described in the method section, step 2 of the inquiry produced an ordering on two main dimensions, portrayed in Figure 1. Rows represent different aspects of the phenomenon of embodied social sensemaking in the context of remote video-conferencing, as found to be relevant for being addressed by the designer-user teams. Columns represent how the interactive qualities of the artifact create different types of scaffold, to be discussed below. Each of the scaffold types (columns) occurred in multiple of the phenomenal aspects (rows), and each phenomenonal aspect was addressed in design using more than one type of scaffold.

\subsection{Social phenomena.}

Six phenomenal aspects of remote embodied social sensemaking were identified: 1) Attending to one another (in particular, managing attention within different parallel conversations), 2) Turn-taking,

\footnotetext{
${ }^{2}$ https://www.mural.co/
} 
Table 1: Brief explanation of main interactions and functionalities for each design case (for reasons of space many details per case have had to be omitted). Letters and titles match Figure 1.

\begin{tabular}{|c|c|c|}
\hline & Title & Explanation of main interaction \\
\hline A & Tangible Audio-channel & $\begin{array}{l}\text { Positioning a physical avatar on a cone shaped tangible represents changing volume levels. Put in } \\
\text { 'wide' zone activates plenary audio, put in narrow zone activates private audio with virtual } \\
\text { 'neighbour' in Zoom interface. }\end{array}$ \\
\hline B & Draw Attention Shoulder Pad & $\begin{array}{l}\text { Interactive pads integrated in clothing. Patting your shoulder to activate a buzz in the remote } \\
\text { persons' shoulder, to catch their attention. }\end{array}$ \\
\hline $\mathrm{C}$ & Embodied Audiochannel I & $\begin{array}{l}\text { Moving closer to tangible next to the screen activates a private audio channel with ones' } \\
\text { immediate (virtual) neighbour, moving away switches to plenary setting (e.g. the teachers' voice). }\end{array}$ \\
\hline $\mathrm{D}$ & Embodied Audiochannel II & $\begin{array}{l}\text { Like } C \text {, but with two objects left and right of the screen representing the person to the left and } \\
\text { right of you in the Zoom interface. }\end{array}$ \\
\hline $\mathrm{E}$ & Turn-taking Harmonica & $\begin{array}{l}\text { Pulling out harmonica sets a timer; harmonica slowly contracts again until it is your time to speak. } \\
\text { Putting tangible on its side unmutes. Pulling of end-piece cancels intention to speak. }\end{array}$ \\
\hline $\mathrm{F}$ & Turn-taking Gavel & $\begin{array}{l}\text { Remote version of traditional gavel. Hitting board activates microphone and mutes others. Putting } \\
\text { on its side mutes oneself. }\end{array}$ \\
\hline G & Turn-taking Microphone & $\begin{array}{l}\text { Remote version of 'passing the mic to give the floor'. Taking mic out of dock activates mic and } \\
\text { mutes others. Putting mic back in dock mutes oneself. }\end{array}$ \\
\hline $\mathrm{H}$ & Interupt Tension Pedal & $\begin{array}{l}\text { User has constant contact with foot on pedal. Putting more pressure on the pedal changes colored } \\
\text { light in the corner of ones' camera image in zoom towards red. Fully red indicates strongly felt } \\
\text { urgency to speak up. }\end{array}$ \\
\hline I & Speaker-Listener POV & $\begin{array}{l}\text { Camera image records posture. Sitting means muting ones' mic. Standing up means activating the } \\
\text { microphone. When standing up the camera moves physically upwards for proper video image of } \\
\text { person. }\end{array}$ \\
\hline $\mathrm{J}$ & Tangible Video Avatars & $\begin{array}{l}\text { Wireless tangibles with screens show camera feed of each participant. Organizing them in spatial } \\
\text { clusters creates break-out rooms. Putting a tangible on the stage activates plenary audio and } \\
\text { centralized video on computer screen ('standing in front of class') }\end{array}$ \\
\hline K & Ask a Question Pen & $\begin{array}{l}\text { Pen with accelerometer records movement patterns. Up-sweep activates question icon in Zoom } \\
\text { interface. }\end{array}$ \\
\hline $\mathrm{L}$ & Physically Distributed Breakout Rooms & $\begin{array}{l}\text { Wireless tangibles that one puts in ones' own physical living space represent virtual 'breakout } \\
\text { rooms' (sub-groups). Moving ones' body to a tangible means moving into that breakout room in } \\
\text { Zoom. }\end{array}$ \\
\hline M & Tangible Emotion Symbolizer & Soft tangible can be squeezed in different ways to activate basic emotion icons in Zoom interface. \\
\hline $\mathrm{N}$ & Remote Appraisal Gestures & $\begin{array}{l}\text { Hand wearable allows for traditional hand gestures to activate corresponding emoticon hands in } \\
\text { Zoom interface (e.g. 'raise hand', 'thumbs up', 'wave'). }\end{array}$ \\
\hline $\mathrm{O}$ & Pat on the Shoulder Pad & $\begin{array}{l}\text { Patting an object on the table activates soft buzz in shoulder pad at remote end, indicating a } \\
\text { reassuring 'pat on the shoulder'. }\end{array}$ \\
\hline $\mathrm{P}$ & Read the Room Ambilight & $\begin{array}{l}\text { Machine learning of facial expression of Zoom image is fed into illuminated object representing } \\
\text { 'the mood in the room'. There is no explicit representation: people gradually make sense of a } \\
\text { peripheral illuminated background. }\end{array}$ \\
\hline Q & Remember your Friends Board & $\begin{array}{l}\text { Interactive objects on wall represent distant friends. Physical flag up means they desire a chat. The } \\
\text { object frontside is first personalized by other, and sent to you over mail, thus carrying emotional } \\
\text { value. }\end{array}$ \\
\hline $\mathrm{R}$ & Touch for Chat Flowerpots & $\begin{array}{l}\text { Touching flowerpot illuminates remote paired flowerpot and indicates a desire to chat. Not } \\
\text { returning call makes the flowerpot slowly 'wane' (change color). }\end{array}$ \\
\hline S & Explorative Social Touch & $\begin{array}{l}\text { An object with randomly placed 'touchpoints' can be explored by the hand, activating lights in the } \\
\text { touchpoints of the remotely paired object, inviting an explorative interaction between remote } \\
\text { hands. }\end{array}$ \\
\hline $\mathrm{T}$ & Remote Warmth by Touching Feet & $\begin{array}{l}\text { Moving feet over a sheet generates isomorphic patterns of warmth at the remotely paired sheet of } \\
\text { a partner, enabling remote touching of feet. }\end{array}$ \\
\hline $\mathrm{U}$ & Spice up the Room Ball & $\begin{array}{l}\text { By throwing your own ball in the air, the balls of one other person lights up and makes a cheerful } \\
\text { sound inviting them to participate more actively. }\end{array}$ \\
\hline $\mathrm{V}$ & Tangible Polls & $\begin{array}{l}\text { Holding up physical coloured card means casting vote in a poll. Image recognition counts votes } \\
\text { and presents results in online poll interface. }\end{array}$ \\
\hline $\mathrm{W}$ & Remote Drinking Party & $\begin{array}{l}\text { Glass augmented with ring and tangible dock allow for 'clinking' to say cheers in remote 'after } \\
\text { work'- drinking party. }\end{array}$ \\
\hline $\mathrm{X}$ & Remote physical board game & $\begin{array}{l}\text { Changing a pin in the board activates light in corresponding hole at remote board. Various games } \\
\text { can be played to strengthen emotional contact. }\end{array}$ \\
\hline
\end{tabular}




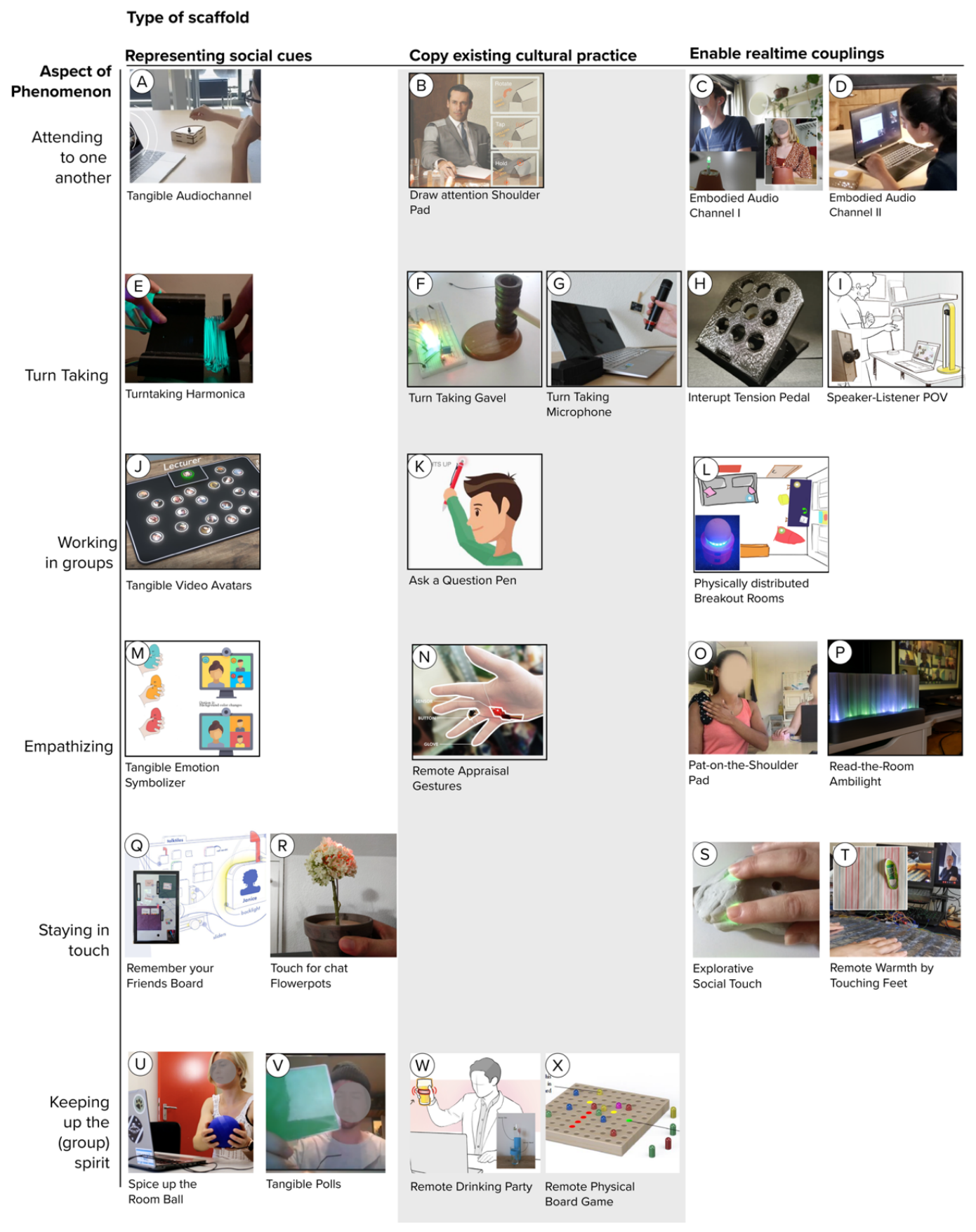

Figure 1: A design space for scaffolding remote embodied social sensemaking. Explanation in text.

3) Working in groups, in particular, forming and moving in- and out subgroups 4) Mutual empathy and sharing emotion, 5) 'staying in touch' and 6) Keeping up the group spirit (see Figure 1, rows). Some phenomenal aspects are naturally present in face-to-face practices, in which case the design question became how to enable or strengthen these aspects remotely. For example, 'Attending. . ' draws from the way physical classrooms afford attending to both a plenary conversation as well as quick, informal 'side conversations'. Similarly, 'Working in groups' is based on how physical spaces allow for quick ad hoc group formation, which supports social coordination. Other themes were (in part) inspired by new social practices that are emerging around video-conferencing technology itself. For example, some projects in 'Turn-taking' investigated and took inspiration from how people have been starting to use the 
'mute' button. The mute button originally functions (and still does) to avoid auditory feedback. But it has also become a distributed management tool for turn-taking. While one person speaks, others mute, much like passing around a 'talking stick'. The mute button also configures subtler forms of social sensemaking. For example, seeing a person unmute themselves right at the moment one intended to speak can be taken as a signal to hold back oneself, or instead to speak up even quicker and louder, so as to make sure one gets the turn. Once this new practice of 'turn-taking by muting' is identified it becomes open to improvement, and the embodied designs in this category aim to do so. Finally, several phenomenal aspects relate to personal experiences of interacting socially in remote settings, which are often not just functional but also emotional. This is shown in designs that address how people in real life can be 'in touch' or 'connecting' in ways that seem more difficult through a screen (Mutual empathy and Staying in Touch). Design was used create embodied ways of 'connecting' beyond video, audio, or text. In this regard, 'Keeping up the group spirit' is also worth mentioning as related to Zoom fatigue and the depressing effects of isolation as a direct effect of the pandemic [49].

\subsection{Types of scaffolding.}

We now turn to the different ways in which the artifacts scaffolded embodied social sensemaking. In what follows, please refer to the column headings and the symbols A-X in Figure 1 and the descriptions in Table 1

4.2.1 Copy existing cultural practice. Several designs instantiate a physical-digital version of a familiar use object that is known to have a certain functional role in 'real life' social cultural convention, such as described in the classic work of Goffman, and the phenomenology of Schutz [50], [51]. The aim is to reenact the role of the object in the familiar social ritual in the remote context, thereby increasing the quality of social interaction in remote settings. For example, (F) reproduces the use of a gavel to manage turn taking in formal meetings. (B) enables a remote 'pat on the shoulder' to draw a person's attention. Note that copying a practice can produce viable results but the designer at the same time essentially copies a successful 'black box' and we do not necessarily know exactly why this object and its associated ritual are functional in sustaining social interaction.

4.2.2 Representing socially relevant information. Another pattern that emerged builds on first getting clear on what is socially relevant information that is assumed to be useful for guiding appropriate action. The designed artifact is then used to represent this information to the user in an accessible way. Sometimes this means to create an embodied interface to enhance accessibility to existing digital functions of the communication technology, which makes it a case of classic 'tangible interface design' [52]. For example, (E) embodies various tangible interface elements that may render existing social functions in Zoom such as 'mute', 'unmute', 'raise hand', 'lower hand' more intuitive (Figure 2).

Sometimes embodied interactions represent (and thereby make more explicit) aspects of the social interaction that would not normally be visible. For example, in (R) a flowerpot represents a distant friend, and its illumination represents the friend is thinking of you

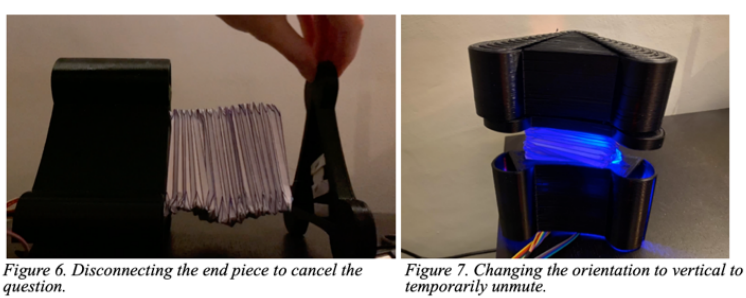

Figure 2: (left) cancelling a question by unlocking the endpiece, (right) unmuting by putting on the side.

and may wish to chat (activated by touching their flower). Touching the flower in return illuminates their flower, together supporting social-affective memory (cf. [53])

4.2.3 Mediate couplings. A third type of scaffold implements ways to catalyse and sustain the emergence of realtime action-perception couplings. In a social setting we find couplings between the flows of action and perception of each of the participants engaged in a social interaction. The 'realtime coupling' scaffold highlights embodied theory that emphasizes social interaction as a self-organizing, improvised interactive process, which is most clearly described in enactivism [10] and relates to the phenomenology of 'skilful embodied coping' [54]. Both (C) and (D) independently came to the concept of a dynamic audio-channel for focusing attention to parallel conversations: if a user leans into a physically placed speaker-microphone, they can speak with their immediate virtual 'neighbour', while if they lean the other way, they hear the 'plenary conversation' in the larger group. Another example of scaffolding realtime coupling is a foot pedal $(\mathrm{H})$ with which one can express a felt tension of wanting to interrupt, while another person is speaking. The pressure maps onto a continuously changing colored light placed in the video-interface of each participant. The changing colours help other speakers (in particular, the active speaker) attend to each other and allow for smooth turn taking. Both examples illustrate how the ongoing action flow of the body of one person gets coupled, as scaffoled by the design, to the perceptual flow of another person, and vice versa. This then allows for the emergence of self-organizing stabilities as described in participatory sensemaking theory [10].

\subsection{Contrasting types of scaffolding.}

For reasons of space, we can only point out a few basic comparisons to illustrate how the framework works as a reflective tool. Again, please refer to symbols A-X in Figure 1

4.3.1 Contrasting scaffolds for attention. Three projects (A, C, D) focused on dividing attention between conversations. In real life, people enact embodied strategies for ad hoc shifting attention. These break down in videoconferencing. Standard applications only offer the rigid option of 'breakout rooms'. Recent applications like "Mozzilla Hubs" are GUI-based attempts to improve on this. In practice, students indicated they often create ad hoc video-channels channels with peers 'on the side', which however increase cognitive load and give rise to miscommunication. If we contrast the designs, we see how (A) instantiates a representation of 'the audio-space' such that one can 'place oneself in the space' to select the desired 
audio setting: from focused and 'nearby' (one hears only ones virtual 'neighbour') to a plenary hall setting. By contrast, (B) and (C) focus on the same phenomenal aspect yet use a different type of scaffolding than in (A). In B and C, the physical distance of the real human body to a tangible object is used to dynamically change the volume settings. While in (A) 'relevant aspects' of the situation are represented in the tangible objects (so the user can see them and act on them) in (B) the experienced meaning emerges from dynamic relation between the user's actions and the object, and through that object, in the dynamic relations between the human bodies who are in social interaction.

4.3.2 Contrasting scaffolds for turn-taking. Projects (E - I) addressed turn-taking. While the turn taking microphone $(\mathrm{G})$ copies a known practice of giving the floor to whomever holds the microphone, the turn-taking harmonica (E) abstracts away from existing practices and introduces new, tangible representations of socially relevant actions. It addresses typical breakdowns in remote videocommunication. It was observed that people often feel a rising desire to speak, yet also do not want to be obtrusive. At the same time, the normal subtle signs that might work in a physical encounter often go unnoticed on video. Also, the desire to speak may disappear as the conversation unfolds. Stretching and contracting the harmonica in (E) represents the felt urgency or 'desire' to speak, not unlike setting a kitchen timer. This same phenomenon was actually addressed in the turn-taking pedal $(\mathrm{H})$. However, here the type of scaffolding is different. The pedal allows for continuously and, over time unreflectively, expressing the urgency to speak by way of a direct bodily comportment to the social situation. There is of course a re-presentation of the pedal pressure into a digital signal at the remote site (a colour on the screen), yet this is not aimed at an explicit sending of a message rather than it is to sustain a continuous channel of ongoing interactions, through which people can resonate in ways similar to the way human bodies resonate in physical settings, as explained in participatory sensemaking theory [10].

4.3.3 Other contrasts. Other phenomenal aspects show similar contrasts. For example: 'Staying in touch', tangibles are designed to represent distant friends $(\mathrm{Q}, \mathrm{R})$. This contrasts with the remote touch using the hands in (S) or the feet in (T). In 'Working in Groups' (J) provides a miniature model of a classroom, with tangibles representing people. (L) instead allows moving oneself into a group by physically moving to one of the tangible objects in ones' physical space: each tangible represents a subgroup. (L) is placed in 'embodied coupling', to highlight that, unlike (J), it utilizes personally meaningful space: users place tangibles in their own home in improvised ways that (only) makes sense to them ('the part of the couch up to the second coffee-stain, is my group'). In (L), sensemaking hinges on personal, contingent lifeworld couplings [55], whereas in $\mathrm{J}$ it relies on generic spatial cognition strategies, such as: 'things close together, belong together' [7].

\section{GENERAL DISCUSSION}

This study produced further detail adding to design frameworks of embodied sensemaking, focusing on its social aspect, and how to scaffold social embodied sensemaking in remote settings. A design space is presented in the form of a matrix that shows 1) various aspects of the phenomenon that invite the design of an embodied technological scaffold and 2) three types of scaffolding are distinguished that embodied technologies may provide.

Concerning the aspects: Van Dijk and Hummels point out that embodied sensemaking is a strongly social phenomenon, drawing mostly participatory sensemaking theory. They indicate that this process can be scaffolded: "People use the public world of objects and artifacts, including their own physical bodies, as scaffolds for participatory sensemaking" [11]. In the context of remote social interaction between people in an educational setting, participatory sensemaking turns out to show various aspects having to do with managing a conversation in realtime, being able to easily move inand out of social subgroups, and sustaining emotional connection ties (staying 'in touch').

Concerning the types of scaffolding: A designer can (and perhaps should) move freely between types of scaffold in their explorations. Copying an existing artifact that already configures a social practices in traditional face-to-face settings might provide an intuitive starting point. As Bill Gaver wrote in 1992: "it is still a typical aim of design to capture in new media at least some of the characteristics of their everyday precursors ... [which] is useful for motivation and learning: Inventions that modify existing practices tend to be easier to conceive and more practical to implement than those that create wholly new functions." [56].

A second type of scaffold is to design new mappings between embodied forms and social meanings, i.e. creating tangible and embodied representations of aspects of the social situation that seem important for people to attend to. Note that such mappings are always to some extent arbitrary: one could have designed it otherwise. Creating representations that provide accurate information about the situation at hand seems a valid goal for interface design. However, this approach may also distract from the role that artifacts in general turn out to have in embodied social sensemaking. In fact, the more promising designs may be not so much those focusing on accurate representation but those eliciting interactions that invite and enable people to gather around and engage in shared activities. Such interactive objects can be binding anchors in a situated social activity (see [1]). This means for example to focus on how objects can be publicly available to participants and open for being acted upon by everyone, that is, to focus on what one can, collaboratively, do with the object, rather than what the object 'says'. Example (U) in Figure 1 may be a case in point: a ball that, when thrown, randomly lights up other people's balls, and thereby 'spices up the atmosphere' and draws people together in a shared experience, which provides a common ground for shared sensemaking.

The freedom to explicitly define how a designed form maps onto a particular social aspect one does not have in the third type: 'enabling realtime couplings'. Couplings, and their associated meaningful experiences, always emerge from the interaction itself, in a concrete situation, in a practice. This means to analyse more deeply which coupling patterns already exist in the practice, in what ways these are currently scaffolded, and then to add something new to the mix. Any design introduced here necessarily becomes one element in a larger network of self-organizing elements. The 'sense' that is made through self-organization is not fixed in one predefined mapping, it emerges from the way skilled interacting bodies with their 
current coping habits, embedded in a lifeworld of contingent structure, appropriate the new artifact. Designing for coupling seems to require less a 'reasoning about' and more an iterative probing of- and reflecting on- experiences [3]. Like a dancer or composer, who tries, feels, hears, searches, shapes, and reshapes, designing for embodied couplings means to integrate a new structure into an already existing sensemaking practice, crafting it until 'it makes most sense' [57]. Furthermore, couplings may emerge long after design, when appropriated into actual human practices, which makes them difficult to anticipate in a design project [58]

\subsection{Working with the matrix.}

The strict separation of rows (phenomenal aspects) and columns (types of scaffold) is of course a caricature. In reality designers might integrate various elements or all into a holistic design. The contrast between 'Representing social cues' versus 'Enabling realtime couplings' was highlighted in some detail because especially 'mediating couplings' seems theoretically somewhat underdeveloped in tangible and embodied interaction research, while 'tangible representation' seems to be a much clearer and stronger concept in the literature to date [59]. Rooted in enactivism, ecological psychology and embodied phenomenology, the coupling is a central concept in [4] and elsewhere. Yet it had so far not been made explicit as to why and how particular scaffolds sustain couplings. One explanation for this lack may be precisely because couplings defy representation: creating a detailed explanatory model might not help to get to the heart of how coupling works, and in particular, it may not help designers to design for them. Designing for coupling is hard. It requires a skilled expertise of its own (cf. [3]). That being said, and based on our obviously incomplete study, we provide some pointers for designing for embodied couplings in remote settings:

1. Always design for action: any output to users is designed to afford further action, 'something to engage with' rather than something to passively 'observe' and 'understand' (e.g Figure 1, H).

2. Use the flow of sensory input that the human body already generates by its movement, to help guide a person's attention. Create bodily augmentations, action-affording objects, or environments inviting bodily exploration (Figure 1, C, D).

3. Instead of representing a shared 'virtual space' where 'virtual people' meet, connect the real spaces, where bodies are located, via technological channels (see also [60]). Next step: envision how these channels extend people's bodies all the way until extended bodies envelop each other in one hybrid 'space'.

4. Prevent using human bodies as mere 'input devices' to another (digital- or mind-) world.

5. Make sure the physical spaces where human bodies are situated remain relevant and meaningful for the unfolding remote social interaction. (Figure 1, C, D, S, T)

6. Create conditions that allow for the configuration and emergence of social practices: 'being together' over longer periods of time. Tangible objects can help here, not so much because they represent social content but because they connect people socio-culturally and emotionally (Figure 1, L, O, P, but also to some extend $\mathrm{Q}$ and $\mathrm{R}$ !).

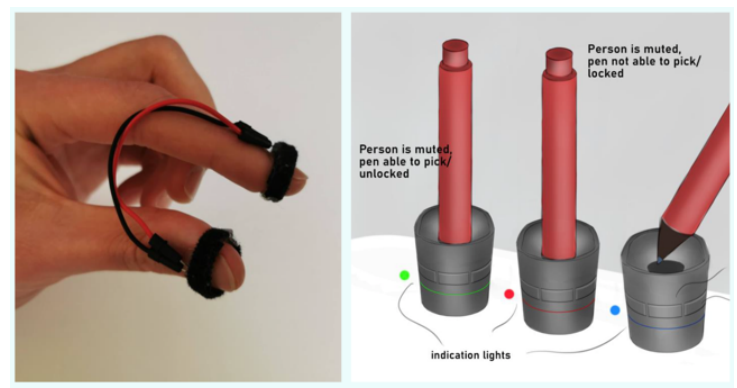

Figure 3: (left) First iteration and (right) second iteration towards the Turn Taking Microphone

7. Allow for appropriation and improvisation by users: your design is one element in a self-organizing network. You are not in control. "You may not be able to design for the unexpected, but you can design to allow the unexpected" [58] (Figure 1, L, P, S T).

\section{LIMITATIONS AND FUTURE WORK}

This work is based on the design work of master students. Working with experienced designer-researchers might have yielded different results. Nevertheless, the design patterns observed do seem comparable to many of the embodied interaction designs in the academic literature. The present study should be seen as a first sketch of structuring aspects of embodied social sensemaking and kinds of scaffolds in a design space, which should be developed further. To give one possible direction for improvement: designs (Q) and (R), are now categorized as 'representing social cues'. Yet this somehow doesn't quite capture their strongly emotional aspect. For example in (R), users are meant to first send each other a personally meaningful object over the mail (a token of affection), which then gets digitally augmented on a wall-mounted 'board' of tangible reminders to friends, which strengthens long-term emotional bonds at a distance. This social-emotional value may warrant clearer visibility (see [53] for work on this topic).

Secondly, we have so far only worked with design outcomes and not looked at process [46]. For example, team F settled early on the gavel, an existing cultural object, while team G first explored a hand-held with forced feedback very similar to the turn-taking pedal $(\mathrm{H})$ before settling on a pen and holder concept, which then changed into the familiar metaphor of the microphone as talking stick (Figure 3). What we may learn from such evolution calls for further analysis in future work.

\section{ACKNOWLEDGMENTS}

Many thanks, and all design credits, to designer-users: Purna Bishas, Anne van den Biggelaar, Marieke Faber, Julia Heuvel, Meike Froklage, Naomi van Stralen, Lara Monteagudo Tubau, Estefanía Moras Jimenez, Wendie van der Meer, Quirien Hover, Anne Elgersma, Jeanne ten Have, Loes van der Werf, Floortje van der Geest, Carithea Richards, Marije Linders, Amy Visscher, Noor Nijrolder, Babette Bosmans, Jasmijn Sagel, Valeria Lopez Rojas, Amelie Nordh, Dorien Brugman, Judith Kampen, Anouk Noordeloos, Tessa Rutjens, Sonali Ori, Laure Tolsma, Andra Mahandra Raditya, Jinming Lyu, 
Hao Yang, Jeroen van Kekem, Maria Noordenbos, Casper Hazebroek, Martijn Poot, Max Pijnappel, Wessel Pit, Bart Sprenkels, Matthijs Mondria, Timo Lempers, Rik de Sain, Pim van Everdingen, Jop Koning, Primaël Quémerais, Sebastian Casillas Perez, Koen Vogel, Coos Pot, Jules Verkade, Finn Prinsenberg, Michel Schmale, Thomas van den Berg and Gemma Ciabattoni.

\section{REFERENCES}

[1] Paul Dourish. 2001. Where the Action Is: The Foundations of Embodied Interaction. MIT Press, Cambridge, MA.

[2] Doug Svanaes. 2013. Interaction Design for and with the Lived Body: Some Implications of Merleau-ponty's Phenomenology. ACM Trans Comput-Hum. Interact., 20, (1), 8:1-8:30. doi: 10.1145/2442106.2442114.

[3] Kristina Höök et al. 2016. Move to be Moved. In Proc. SIGCHI conf. on Human factors in Comp. Sys., CHI'16, Ext Abstr, San Jose, USA, 3301-3308. doi $10.1145 / 2851581.2856470$.

[4] Caroline Hummels and Jelle van Dijk. 2015. Seven Principles to Design for Embodied Sensemaking. In Proc. of the Ninth Int. Conf. on Tangible, Embedded, and Embodied Interaction - TEI '14, Stanford, USA, 21-28. doi: 10.1145/2677199.2680577.

[5] Lucy, Suchman. 2007. Human-Machine Reconfigurations: Plans and Situated Actions. 2nd exp. ed. Cambridge University Press. New York. doi: https://doi.org/ 10.1017/CBO9780511808418.

[6] Toni Robertson. 1997. Cooperative Work and Lived Cognition: A Taxonomy of Embodied Actions. In: Proc. 5th ECCSCW, Springer, Dordrecht, 205-220. doi: https://doi.org/10.1007/978-94-015-7372-6_14

[7] James Hollan, Edward Hutchins, and David Kirsh. 2000. Distributed cognition: toward a new foundation for human-computer interaction research. ACM Trans. Comput.-Hum. Interact., 7 (2), 174-196. doi: 10.1145/353485.353487.

[8] David Kirsh. 2013. Embodied cognition and the magical future of in teraction design. ACM Trans. Comput.-Hum. Interact., 20, (1), 1-30. doi: $10.1145 / 2442106.2442109$.

[9] Jelle van Dijk. 2018. Designing for Embodied Being-in-the-World: A Critical Analysis of the Concept of Embodiment in the Design of Hybrids. Multimodal Technol. Interact., 2, (1), 7 pages, doi: 10.3390/mti2010007.

[10] Hanne de Jaegher and Ezequiel Di Paolo. 2007. Participatory sense-making: An enactive approach to social cognition. Phenomenol. Cogn. Sci., 6, (4), 485-507.doi https://doi.org/10.1007/s11097-007-9076-9.

[11] Jelle van Dijk and Caroline Hummels. 2017. Designing for Embodied Being-inthe-World: Two Cases, Seven Principles and One Framework. Proc. Eleventh Int. Conf. on Tangible, Embedded, and Embodied Interaction, Yokohama Japan, 47-56. doi: 10.1145/3024969.3025007.

[12] Chris Heath and Paul Luff. 1991. Disembodied conduct: communication through video in a multi-media office environment. In Proc. SIGCHI conf. on Human factors in Comp. Sys., CHI '91, New Orleans, USA. 99-103. doi $10.1145 / 108844.108859$.

[13] Virgine Dagonneau, Elise Martin and Mathilde Cosquer. 2014. Collaborating \& being together: influence of screen size and viewing distance during video communication. In Proc. of 2014 Virtual Reality International Conference, Laval France, 1-5. doi: 10.1145/2617841.2620717.

[14] Carman Neustaedter and Saul Greenberg. 2012. Intimacy in long-distance relationships over video chat. In Proc. SIGCHI Conf. on Human Factors in comp. sys, CHI'12, Austin Texas USA, 753-762. doi: 10.1145/2207676.2207785.

[15] Jean Lave and Etienne Wenger. 1991. Situated Learning: Legitimate Peripheral Participation. Cambridge University Press, Cambridge MA.

[16] Jelle van Dijk and Caroline Hummels. 2015. Designing for Participatory Sensemaking. Proc. European Academy of Design Conference, Paris, France.

[17] Antal Haans and Wijnand IJsselsteijn. 2006. Mediated social touch: a review of current research and future directions. Virtual Real., 9, (2-3), 149-159. doi: 10.1007/s10055-005-0014-2.

[18] Scott Brave and Andrew Dahley. InTouch: a medium for haptic interpersonal communication'. In CHI '97 extended abstracts, Atlanta, Georgia, 363-264. doi: 10.1145/1120212.1120435.

[19] Jan van Erp and Alexander Toet. 2015. Social Touch in Human-Computer Interaction. Front. Digit. Humanit., 2. doi: 10.3389/fdigh.2015.00002.

[20] cutecircuit.com. 2004. CuteCircuit receives CyberArt Award 2004. https:// cutecircuit.com/news/cutecircuit-receives-cyberart-award-2004/ (accessed Jul. 31, 2021).

[21] James Teh, Adrian Cheok, Roshan Peiris, Yongsoon Choi, Vuong Thuong and Sha La. 2008. Huggy pajama: a parent and child hugging communication system. In Proc. 7th Int Conf on Interact. Design and Children, 250-257. doi: $10.1145 / 1551788.1551861$

[22] Allan Fong, Zahra Ashktorab, and Jon Froehlich. 2013. Bear-with-me: an embodied prototype to explore tangible two-way exchanges of emotional language. In CHI '13 Ext Abstr on Human Factors in Comp. Sys., CHI EA '13. ACM, New York,
USA, 1011-1016. doi: https://doi.org/10.1145/2468356.2468537

[23] Young-Woo Park, Seok-Hyung Bae, and Tek-Jin Nam. 2012. How do couples use CheekTouch over phone calls? In Proc SIGCHI Conf. Human Factors in Comp. Sys., CHI '12. ACM, New York, USA, 763-766. doi: https://doi.org/10.1145/ 2207676.2207786

[24] Daniel Gooch and Leon Watts. 2012. YourGloves, hothands and hotmits: devices to hold hands at a distance. In Proc. 25th ACM symposium on User interface software and technology, UIST '12, Cambridge (MA), USA, 157. doi: $10.1145 / 2380116.2380138$

[25] Jinsil Seo, Annie Sungkajun, and Meghan Cook. 2017. InTouch Wearables: Exploring Ambient Remote Touch in Child-Parent Relationships. In Proc. Eleventh Int. Conf. on Tangible, Embedded, and Embodied Interaction, Yokohama Japan, 671-676. doi: 10.1145/3024969.3025057.

[26] Janne Beuthel, Philippe Bentegeac, Verena Fuchsberger, Bernhard Maurer and Manfred Tscheligi. 2021. Experiencing Distance: Wearable Engagements with Remote Relationships'. In Proc. Fifteenth Int. Conf. on Tangible, Embedded, and Embodied Interaction, Salzburg Austria, 1-13. doi: 10.1145/3430524.3446071.

[27] Chung, C.-H. J. Lee, and T. Selker, 'Lover's cups: drinking interfaces as new communication channels', in CHI '06 Extended Abstracts on Human Factors in Computing Systems, Montréal Québec Canada, Apr. 2006, pp. 375-380. doi: 10.1145/1125451.1125532.

[28] Dimitris Papanikolaou, Alice Jane Bernheim Brush, and Asta Roseway. 2015. BodyPods: Designing Posture Sensing Chairs for Capturing and Sharing Implicit Interactions. In Proc. Ninth. Int. Conf. on Tangible, Embedded, and Embodied Interaction, Stanford California USA, 375-382. doi: 10.1145/2677199.2680591.

[29] Chris Dodge. 1997. The bed: a medium for intimate communication', In CHI '97 Ext. Abstr. Human factors. in Comp. Sys., CHI '97, Atlanta, Georgia, 1997, p. 371. doi: 10.1145/1120212.1120439.

[30] Kelly Dobson, Danah Boyd, Wendy Ju, Judith, Donath, and Hiroshi Ishii. 2001. Creating visceral personal and social interactions in mediated spaces. In CHI '01 Ext Abstr. on Human factors in comp sys, CHI '01, 151. doi: 10.1145/634067.634160.

[31] Christoffel Kuenen. 2015. Mediating Group Experiences: Designing the InBetween. In Proc. of the Ninth Int. Conf. on Tangible, Embedded, and Embodied Interaction, Stanford California USA, 441-444. doi: 10.1145/2677199.2691605.

[32] Paul Dourish and Sara Bly. 1992. Portholes: supporting awareness in a distributed work group. In Proc. SIGCHI conf. on Human factors in comp. sys., CHI '92, Monterey, California, United States, 541-547. doi: 10.1145/142750.142982.

[33] P. Dourish, Annette Adler, Victoria Bellotti, and Austin Henderson. 1996. Your place or mine? Learning from long-term use of Audio-Video communication. Comput. Support. Coop. Work CSCW, 5 (1), 33-62. doi: 10.1007/BF00141935.

[34] Gerda Smets and Kees Overbeeke. 19994. Industrial design engineering and the theory of direct perception'. Des. Stud., 15 (2), 175-184. doi: 10.1016/0142$694 \mathrm{X}(94) 90023-\mathrm{X}$.

[35] Muhammad Khan, Haibo Li, and Shafiq ur Réhman. 2014. Embodied Tele-Presence System (ETS): Designing Tele-Presence for Video Teleconferencing. In Design, User Experience, and Usability. User Experience Design for Diverse Interaction Platforms and Environments, Cham, 574-585. doi: https://doi.org/10.1007/978-3319-07626-3 54.

[36] Jacob Biehl, Daniel Avrahami, and Anthony Dunnigan. 2015. Not Really There: Understanding Embodied Communication Affordances in Team Perception and Participation. In Proc. 18th ACM Conf. on Comp. Supp. Coop. Work \& Social Comp. Vancouver BC Canada, 1567-1575. doi: 10.1145/2675133.2675220.

[37] Irene Rae, Leila Takayama and Bilge Mutlu. In-body experiences: embodiment, control, and trust in robot-mediated communication. In Proc. SIGCHI Conf. on $\mathrm{Hu}-$ man Factors in Comp. Sys., Paris France, 1921-1930. doi: 10.1145/2470654.2466253.

[38] Jon Hindmarsh, Mike Fraser, Chris Heath, Steve Benford, and Chris Greenhalgh. 2000. Object-focused interaction in collaborative virtual environments', ACM Trans. Comput.-Hum. Interact., 7 (4), 477-509. doi: 10.1145/365058.365088.

[39] Johanna Brewer, Amanda Williams and Paul Dourish. 2007. A handle on what's going on: combining tangible interfaces and ambient displays for collaborative groups. In Proc. 1st Int. Conf. on Tangible and Embedded Interaction, TEI '07, Baton Rouge, Louisiana, 3. doi: 10.1145/1226969.1226971.

[40] Saskia Bakker, Elise van den Hoven, and Berry Eggen. 2013. FireFlies: physical peripheral interaction design for the everyday routine of primary school teachers. Proc. of Seventh Int. Conf. on Tangible, Embedded and Embodied Interaction, Barcelona, Spain, 57-64. doi: 10.1145/2460625.2460634.

[41] Philemonne Jaasma, Jelle van Dijk, Joep Frens and Caroline Hummels. On the Role of External Representations in Designing for Participatory Sensemaking. In Proc. Conf. on Design and Semantics of Form and Movement, DeSForM 2017, InTech. Retrieved December 1, 2021 from http://www.intechopen.com/books/proceedings- of-the-conference-on-designand-semantics-of-form-and-movement-sense-and-sensitivity-desform2017/on-the-role-of-external-representations-in-designing-for-participatorysensemaking. doi: 0.5772/intechopen.71207.

[42] Dorothé Smit, Ruth Neubauer, and Verena Fuchsberger. 2021. Distributed Collaborative Sensemaking: Tracing a Gradual Process. In Proc. Fifteenth Int. Conf. on Tangible, Embedded, and Embodied Interaction, Salzburg Austria, 1-12. doi: $10.1145 / 3430524.3446079$. 
[43] Detlef La Grand. 2020. Spatial.io vs Mozilla Hubs. Medium.com. Retrieved December 1, 2021 from https://medium.com/@detlef_VRmaster/spatial-io-vs-mozillahubs-7327e287244d.

[44] E. Bjögvinsson, P. Ehn, and P.-A. Hillgren, 'Design Things and Design Thinking: Contemporary Participatory Design Challenges', Des. Issues, vol. 28, no. 3, pp. 101-116, Jul. 2012, doi: 10.1162/DESI_a_00165.

[45] Norbert Roozenburg and Kees Dorst. Describing Design as a Reflective Practice Observations on Schön's Theory of Practice. In: Designers, E. Frankenberger H. Birkhofer, and P. Badke-Schaub, Eds. London: Springer London, 1998, 29-41. Retrieved Oct. 13, 2019. from http://link.springer.com/10.1007/978-1-4471-1268 63.

[46] Bart Hengeveld, Joep Frens, and Eva Deckers. Artefact Matters'. 2016. Des. J., 19 (2), 323-337. doi: 10.1080/14606925.2016.1129175.

[47] Kees Dorst. 2011. The core of “design thinking” and its application'. Des. Stud., 32, (6). 521-532. doi: 10.1016/j.destud.2011.07.006.

[48] Pieter-Jan Stappers and Elisa Giaccardi. 2017. Research through Design. The Encyclopedia of Human-Computer Interaction. 2017. Retrieved November 15, 2021 from https://www.interaction-design.org/literature/book/the-encyclopediaof-human-computer-interaction-2nd-ed/research-through-design.

[49] Jeremy Bailenson. 2021. Nonverbal overload: A theoretical argument for the causes of Zoom fatigue. Technol. Mind Behav. 2 (1), doi: 10.1037/tmb0000030.

[50] Ervin Goffman. 1966. Behavior in public places. Simon and Schuster, London

[51] Alfred Schutz, George Walsh, and Frederick Lehnert, 1974. The phenomenology of the social world. Northwestern University Press, Evanston, lllinois.

[52] Hiroshi Ishii. 2008. Tangible bits: beyond pixels. In Proc. 2nd Int. Conf. on Tangible and Embedded Interaction, TEI '08, Bonn, Germany. xv-xxv. doi:
$10.1145 / 1347390.1347392$

[53] Elise van den Hoven, Mendel Broekhuijsen and Ine Mols. 2018. Design Applications for Social Remembering, In M.L. Meade, C.B. Harris, P. van Bergen , J. Sutton, A.J. Barnier. Collaborative Remembering, Vol. 1. Oxford University Press. doi: $10.1093 /$ oso/9780198737865.003.0022.

[54] Hubert Dreyfus. 2002. Intelligence without representation: Merleau-ponty's critique of mental representation. Phenomenol. Cogn. Sci., 1, 367-83.

[55] Philip Agre and Ian Horswill. 1997. 'Lifeworld analysis'. J. Artif. Intell. Res., vol. 6, pp. 111-145.

[56] William Gaver. 1992. The affordances of media spaces for collaboration. In Proc. 1992 ACM confe. on Comp.-Supp. Coop. Work., CSCW '92, Toronto, Ontario, Canada, 17-24. doi: 10.1145/143457.371596.

[57] Caroline Hummels. 2012. Matter of transformation. Sculpting a valuable tomorrow. Inaugural lecture. Eindhoven: University Press, 2012.

[58] Alan Dix. 2007. Designing for Appropriation. Proc. 21st Br. HCI Group Annu. Conf. People Comput., 2, 27-30.

[59] Jelle van Dijk, Remko van der Lugt, and Caroline Hummels. 2014. Beyond Distributed Representation: Embodied Cognition Design Supporting SocioSensorimotor Couplings. in Proc. of Tangible, Embodied and Embedded Interaction Conference, TEI'14, München, 181-188. doi: https://doi.org/10.1145/2540930. 2540934.

[60] Daniel Gooch and Leon Watts. 2011. A Design Framework for Mediated Personal Relationship Devices. In Proc. of HCI 2011, 25th BCS Conf. on Human Computer Interaction, Newcastle upon Tyne, UK, 237-242. doi: 10.14236/ewic/HCI2011.52. 